\title{
A New Small Dual-Band Elliptical Microstrip Antenna for Ku/K Band Satellite Applications
}

\author{
Mohamed Mahfoudh Harane ${ }^{1}$, Hassan Ammor ${ }^{2}$ \\ ${ }^{1,2}$ Smart Communications Research Team, Engineering for Smart and Sustainable Systems Research Center, EMI, \\ Mohammed V University, Rabat, Morocco.
}

\begin{tabular}{l}
\hline Article Info \\
\hline Article history: \\
Received Feb 7, 2019 \\
Revised Aug 19, 2019 \\
Accepted Sep 13, 2019 \\
\hline
\end{tabular}

\section{Keywords:}

Patch antennas

Dual band

$\mathrm{Ku} / \mathrm{K}$ band

Satellite antennas

Satellite applications

\begin{abstract}
In this paper a new design of a dual small band small elliptical microstrip antenna is proposed for $\mathrm{Ku}$ and $\mathrm{K}$ band satellite applications. The basic antenna structure is an elliptical patch with inset-feed, which is modified by adding two rectangular slots in the radiation patch. The proposed antenna has been designed and fabricated on $1.58 \mathrm{~mm}$ thick FR4 substrate whose dielectric constant is 4.4 , with dimensions of about $10 \times 12 \times 1.58 \mathrm{~mm}^{3}$. The antenna structure was validated using two different electromagnetic solvers and by measuring the results using a Vector Network Analyzer (VNA). The measured and simulated results show two resonant frequencies that define two bandwidths. Moreover, the proposed antenna frequency bands and the consistent and symmetrical radiation patterns make it an appropriate candidate for many applications such as the $\mathrm{Ku} / \mathrm{K}$ band satellite application and wireless communications.
\end{abstract}

Copyright (C) 2019 Institute of Advanced Engineering and Science. All rights reserved.

\section{Corresponding Author:}

Mohamed Mahfoudh Harane,

Smart Communications Research Team (ERSC), Engineering 3S Research Center,

Mohammadia School of Engineering

Mohammed V University in Rabat

Avenue Ibn Sina, B.P. 765 Agdal, Rabat, Maroc

Email: med_mhfd.harane@research.emi.ac.ma

\section{INTRODUCTION}

The space industry has developed considerably and offers very interesting prospects with more than 100 new satellites launched each year. About twenty of them are dedicated to the telecommunications sector, which shows the good economic condition of this sector. [1]

On a global scale, satellite radio connections are a universal communication support. They are also used for mobile applications such as communications to airplanes or ships to which it is impossible to use cable. [2] The best-recognized applications are international telephony, essential when travelling in remote regions, the direct reception of hundreds of television channels or the transmission of real-time data between stock exchanges, banking networks and large companies in our globalized economy. Isolated populations can also benefit from distance learning or receive valuable medical advice through the development of telemedicine. [3-5]

This development of space telecommunications has brought to light the growing need for inexpensive and space-saving microwave devices, which make use of microwave antenna technology. Printed antennas generally use a single layer of substrate, and are widely used in microwave and millimeter wave applications. They are in any geometric form and are arranged on a dielectric substrate and a ground plane. These radiating elements have different shapes: rectangular, square, circular, triangular, elliptical or other more complex shapes depending on the applications envisaged [6-8]. Furthermore, the patch antenna is construct from conductive material; the substrate dielectric constant $\epsilon_{\mathrm{r}}$ is generally in the range $2.2 \leq \epsilon_{\mathrm{r}} \leq 12$ and the height $h$ usually in range $0.003 \lambda_{0} \leq \lambda_{0} \leq 0.05 \lambda_{0}$; where $\lambda_{0}$ is the free space wave length $\lambda_{0}=0.145$. 
To achieve multi-application operation with different frequencies at the same time, we use a multiband antenna where the same antenna can be used to operate at multiple frequencies [9-11]. This reduces the manufacturing costs by avoiding space limitation problems and minimizing the antenna size. In the dual-band patch antenna, the same antenna operates at two different resonant frequency and thus red minimizing the size of the antenna [11-18].

In this paper, a new small dual-band elliptical microstrip antenna that can be integrated in the satellite communication devices for $\mathrm{Ku}$ and $\mathrm{K}$ band. The proposed antenna is printed on FR4 substrate. The result shows that the bandwidths remain very similar with a good agreement between the simulations and the measurements.

Compared to other dual band microstrip antennas [14 -18], our antenna has the advantage of its small size, high gain and high bandwidth.

\section{ANTENNA DESIGN}

Initially an elliptical patch antenna is considered with inset-feed, and then we add two rectangular slots in the radiation patch to determine the resonant frequencies, by regulating the effects of electromagnetic coupling between the patch and the ground plane.

Finally, the geometry of the proposed elliptical dual-band microstrip patch antenna is shown in Figure 1. The proposed antenna is applied and printed on the dielectric material FR4 substrate with a thickness $\mathrm{h}=1.58$ $\mathrm{mm}$, relative permittivity $\varepsilon_{\mathrm{r}}=4.4$ and Tangent loss $\delta=0.02$.

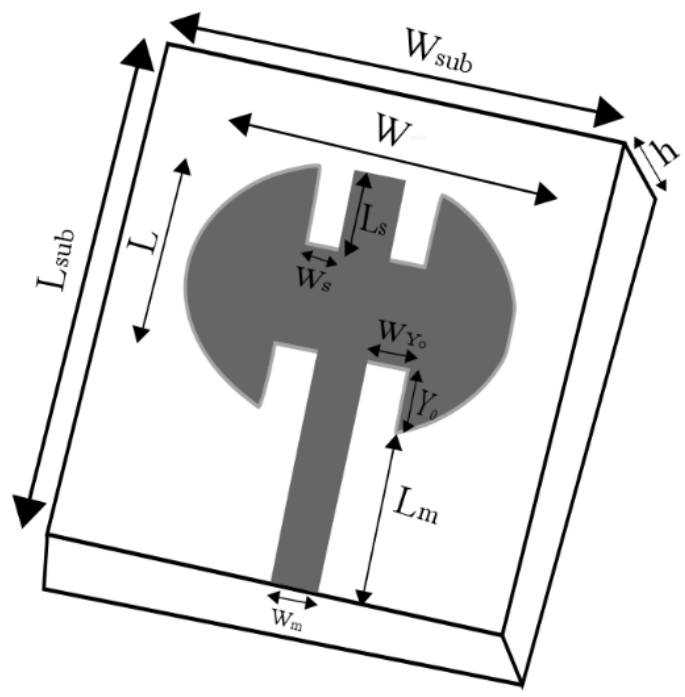

Figure 1. Geometry of the proposed antenna

The final parameters calculated and optimized of the proposed antenna through EM simulations for $14 \mathrm{GHz}$ operating frequency are shown in Table 1.

Table 1. Design Parameters of the Proposed Antenna

\begin{tabular}{ccc} 
Parameter & Description & Values $(\mathrm{mm})$ \\
\hline $\mathrm{W}$ & Width of Patch & 7 \\
$\mathrm{~L}$ & Length of Patch & 5 \\
$\mathrm{Wsub}$ & Width of Substrate & 12 \\
Lsub & Length of Substrate & 10 \\
$\mathrm{~h}$ & Height of Substrate & 1.58 \\
$\mathrm{Wm}$ & Microstrip Feed Width & 1.5 \\
$\mathrm{Lm}$ & Microstrip Feed Length & 4 \\
$\mathrm{Wy}$ & Inset Width & 0.75 \\
$\mathrm{Ly} \mathrm{y}_{0}$ & Inset Length & 1.5 \\
$\mathrm{Ws}$ & Width of therectangular slot & 0.5 \\
Ls & Length of the rectangular slot & 2 \\
\hline
\end{tabular}




\section{RESULTS AND DISCUSSIONS}

The proposed antenna performance was studied by using an electromagnetics solvers based on the finite element method (FEM), which is $\mathrm{HFSS}^{\mathrm{TM}}$ and $\mathrm{CST}^{\mathrm{TM}}$. To validate our antenna design, we designed and simulated the same structure using another solver based on the finite integration technique (FIT). Figure 2 illustrates the $\mathrm{S}$ parameter obtained from both simulation tools.

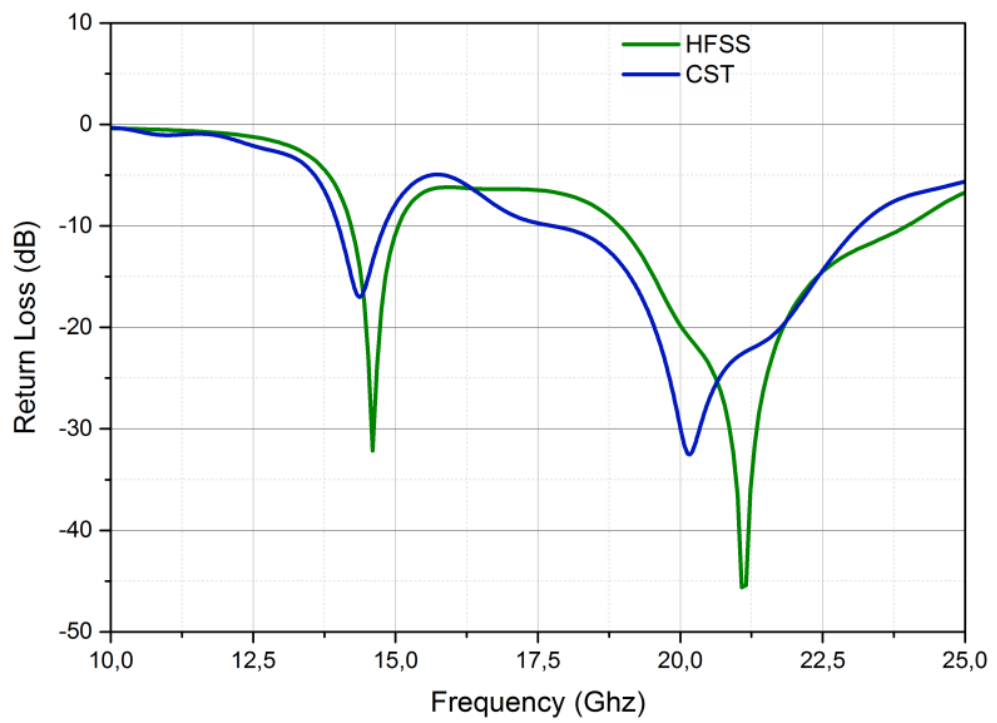

Figure 2. Comparison between the S parameter simulated of the proposed antenna

The $\mathrm{S}$ parameter $\left(\mathrm{S}_{11}\right)$ curve shows that the proposed antenna resonates at $14.59 \mathrm{GHz}$ with a bandwidth of $830 \mathrm{MHz}(14.22-15.05 \mathrm{GHz})$ where it can operate as an Ku-band antenna and at $21.08 \mathrm{GHz}$ with a bandwidth of 5,12 GHz (18.92-24.02 GHz) where it can be used as an K-band antenna for satellite applications. The maximum return loss of $-32.13 \mathrm{~dB}$ and $-45.62 \mathrm{~dB}$ is obtained at the resonant frequencies of $14.59 \mathrm{GHz}$ and $21.08 \mathrm{GHz}$ respectively.

The comparison between the S parameter simulated in Figure 2, shows a difference in return loss obtained from the two simulation tools, and we can observe that we have almost the same frequency bands, with high frequency resonance is slightly moved. This difference in return loss is due to the calculation technique used in each simulation software.

To evaluate our design, we simulate and measure antenna gain, radiation pattern and bandwidth at different resonant frequencies.
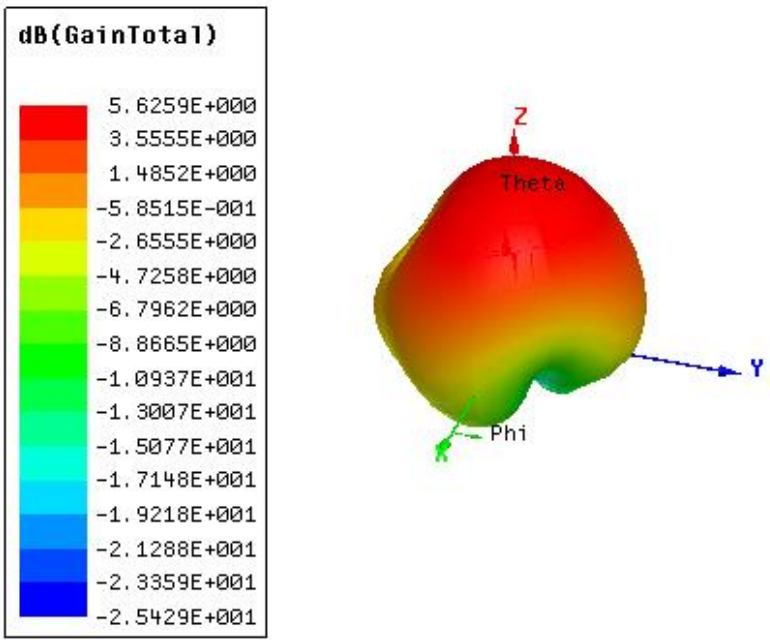

Figure 3. 3D radiation pattern at $14.59 \mathrm{GHz}$ 

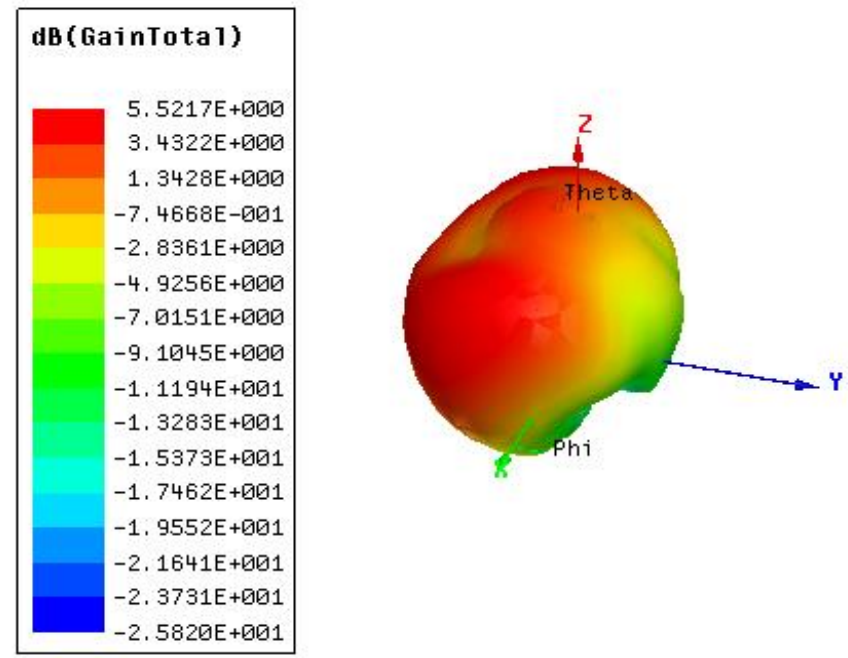

Figure 4. 3D radiation pattern at $21.08 \mathrm{GHz}$

Figure 3 and Figure 4 show the 3D radiation pattern at the first resonance frequencies and that at the second frequency successively. As mentioned in previous figures, it also shows an acceptable value of gain which can be considered adequate and stable for our antenna, which can be used as the basic element for an antenna array for a satellite reception application.

Figure 5 and Figure 6 show the 2D radiation pattern (xz-plane and yz-plane) at different resonating frequencies. The proposed antenna corresponding radiation efficiencies are practically acceptable and the antenna is nearly omnidirectional at the different resonating frequencies. From this, it is concluded that the antenna is well appropriate for the wireless communication applications.

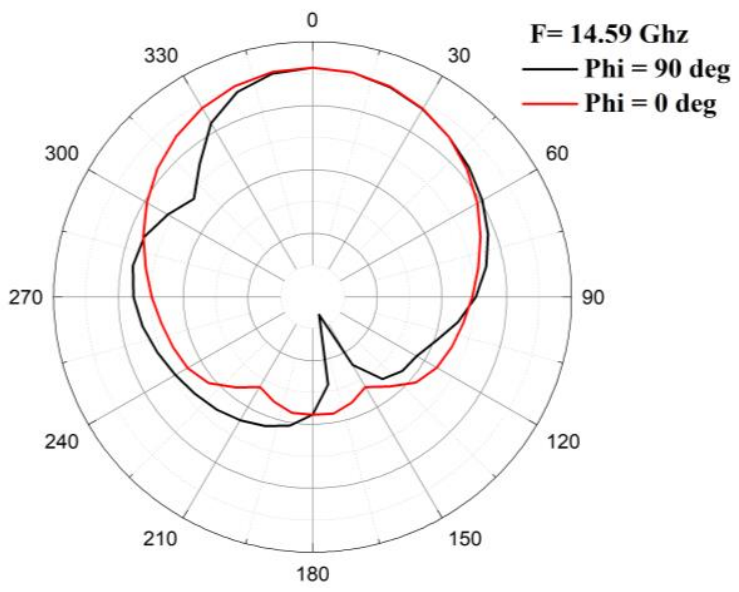

Figure 5. Radiation patterns at $14.59 \mathrm{GHz}$

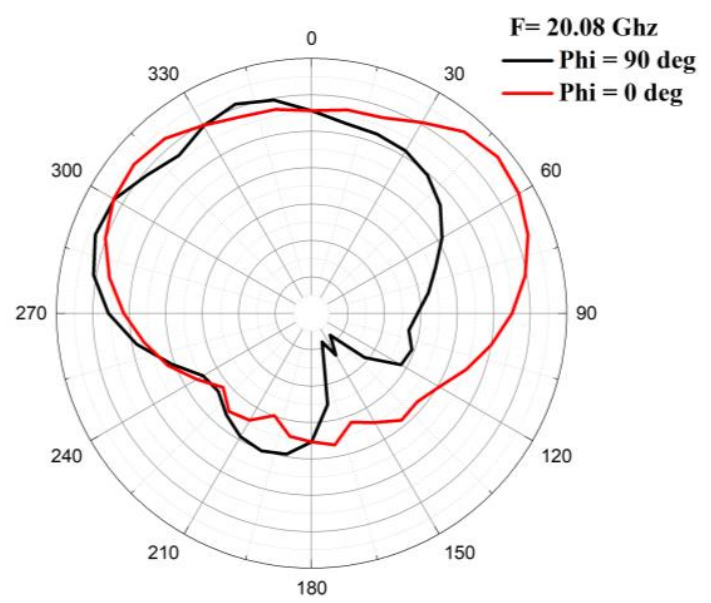

Figure 6. Radiation patterns at $20.08 \mathrm{GHz}$

Figure 7 shows the variation of the gain and the efficiency versus frequency. The gain of the proposed antenna has certain stability over the operating frequency bands, and has a maximum value of $7.4 \mathrm{~dB}$ at 18.89 $\mathrm{GHz}$, which is better than that given in reference. The gain is relatively good and can be improved by making an array of antennas of our prototype. The efficiency was obtained from gain and directivity. An overall level of about $80 \%-92 \%$ can be attained in the bands of frequencies of the proposed antenna.

After the optimization of the dual band elliptical antenna, and based on the optimized dimensions shown in Table 1, the physical prototype of the proposed elliptical antenna was fabricated on FR4 substrate using the LPKF machine. Then measured to verify experimental data and analyzed.

A photograph of the fabricated dual-band elliptical antenna is shown in Figure 8. For the measurements of our prototype, we use the Universal Test Fixture, Anritsu $3680 \mathrm{~V}$, [19] as shown in Figure 9, which gives us 
a precise and reproducible transition from coaxial to microstrip antenna. This provides us with precise and repeatable solutions for prototype measurement.

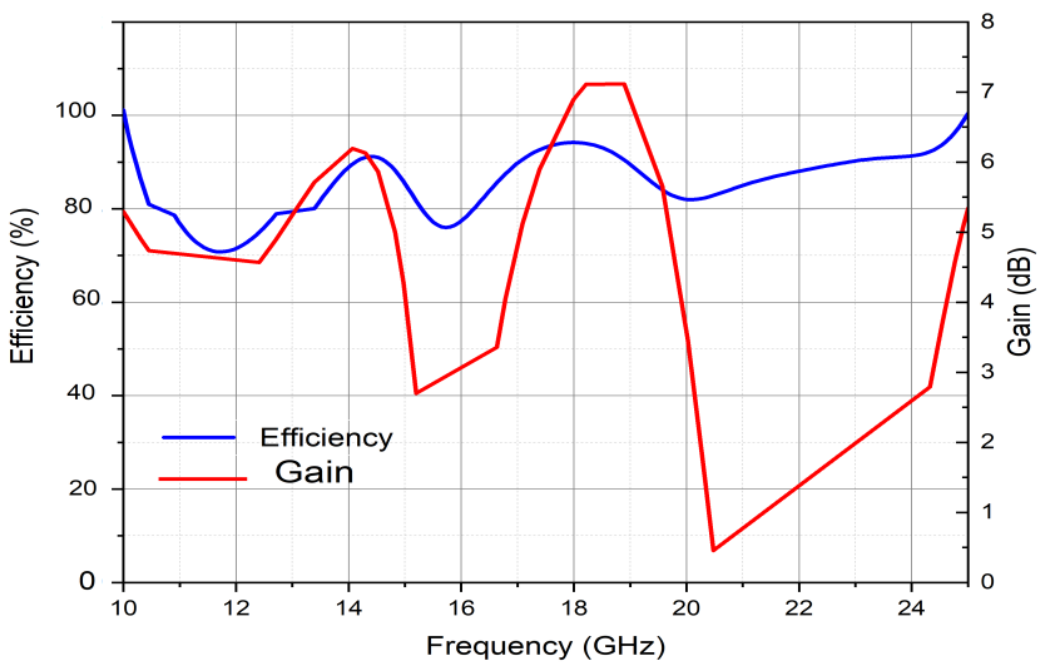

Figure 7. The gain and efficiency of proposed antenna

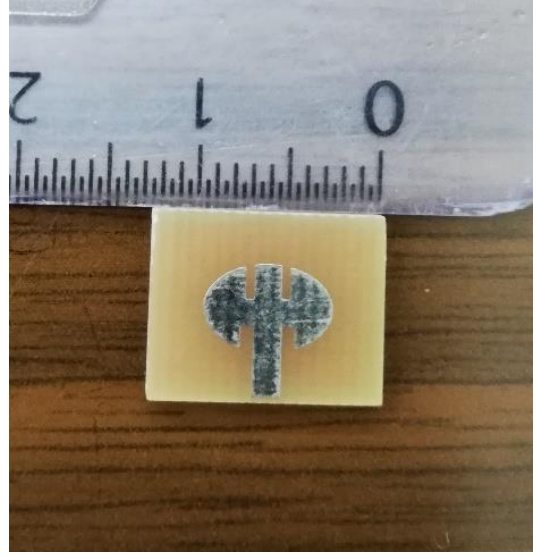

(a)

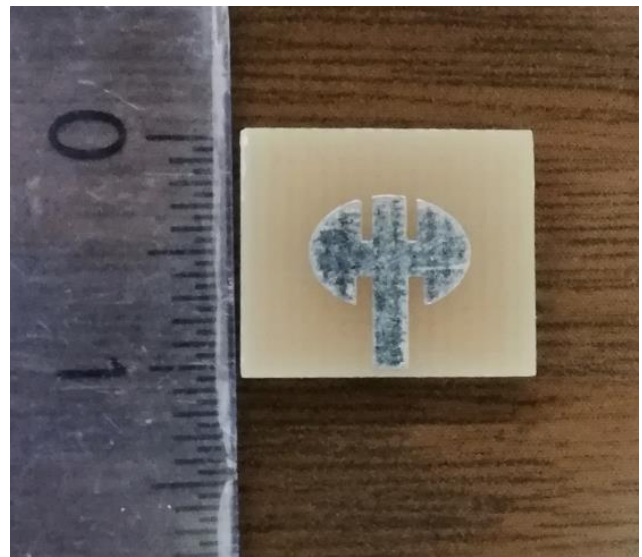

(b)

Figure 8. Fabrication Result of Microstrip Antenna (a) width of antenna (b) Length of antenna

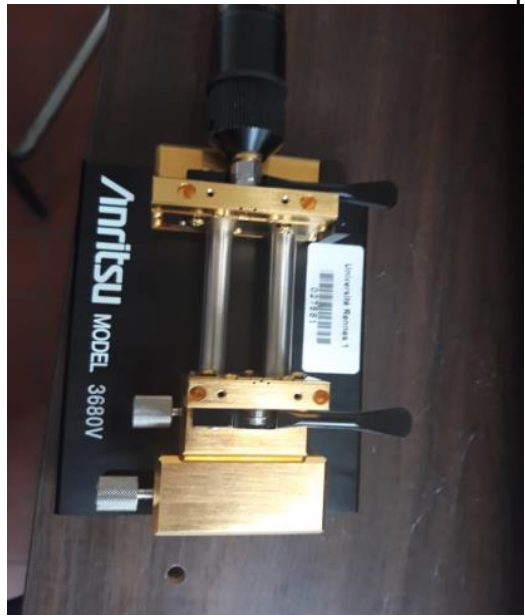

(a)

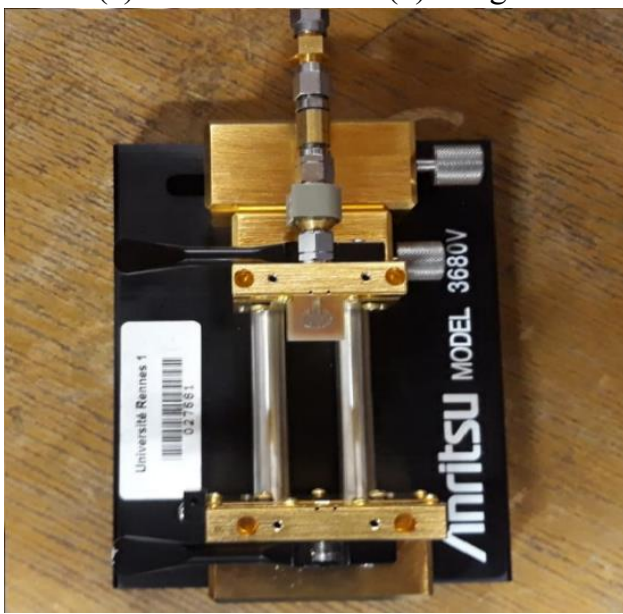

(b)

Figure 9. (a) The Anritsu $3680 \mathrm{~V}$ (b) Fabricated antenna with the the Universal Test Fixture

A New Small Dual-Band Elliptical Microstrip Antenna for Ku/K Band ... (MM Harane et al) 
As shown in Figure 10, the $\mathrm{S}$ parameter $\left(S_{11}\right)$ of the fabricated dual-band elliptical antenna was measured by using a Vector Network Analyzer. After the calibration, as shown in Figure 11, the return loss of the fabricated dual-band elliptical antenna is measured and compared with the parameters obtained by using CST-MW and HFSS.

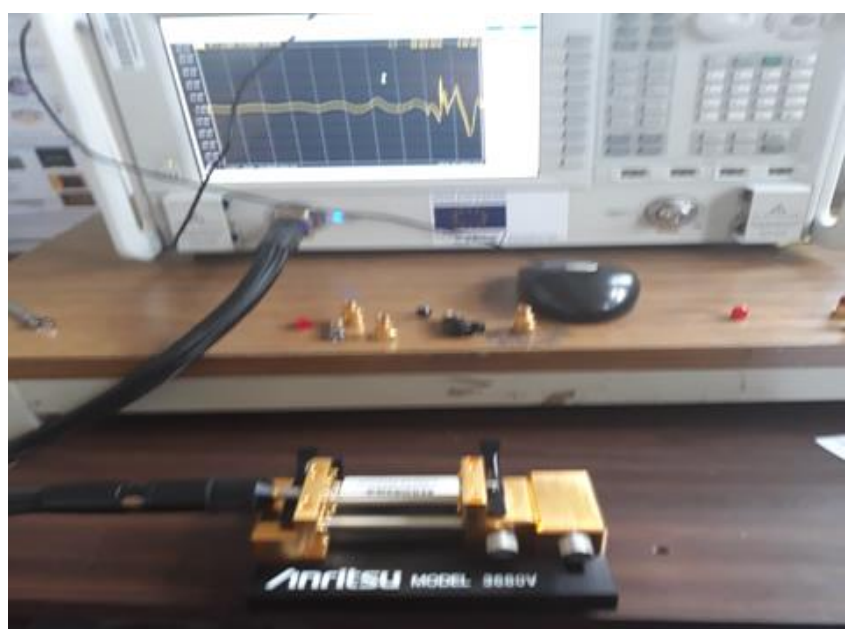

Figure 10. The measurements of the antenna fabricated with VNA

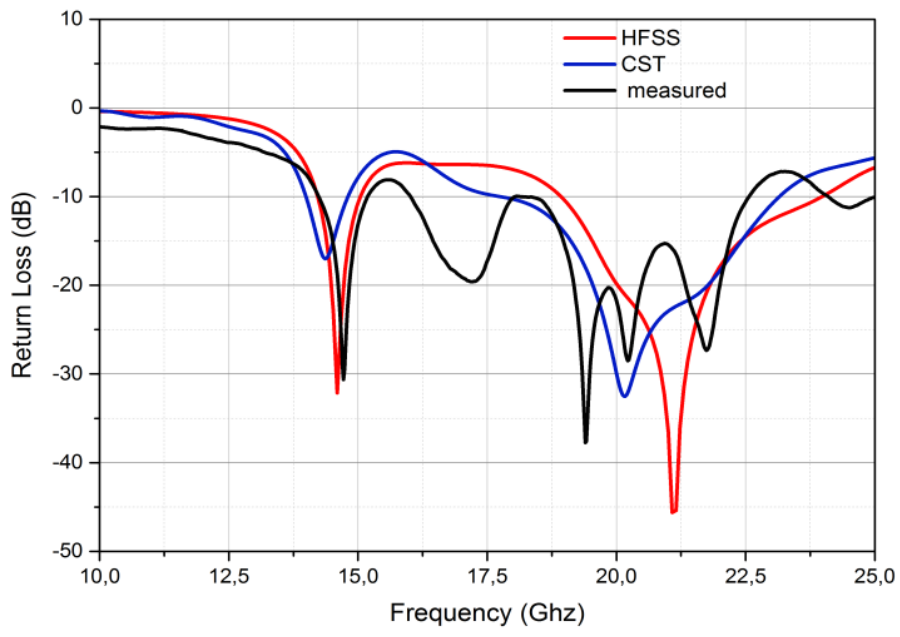

Figure 11. Comparison of measured and simulated return loss

The comparison shows that the bandwidths remain very similar with a good concordance between simulations and measurements, allowing the accuracy of the simulation to be verified.

The small difference between the simulated and measured results may be due to the errors of the fabricated antenna and the Anritsu $3680 \mathrm{~V}$, which is included in the measurements but not taken into consideration in the calculated results. In addition, a small deviation with a resonance frequency offset is observed in the high frequencies, due to the effects of the substrate FR4 used for manufacturing, the manufacturing imperfection and the cable during measurements.

Table 2. Characteristics of the proposed antenna

\begin{tabular}{cccc}
\hline \multirow{2}{*}{ Solvers } & $\begin{array}{c}\text { Bandwidth at }-10 \mathrm{Db} \\
(\mathrm{GHz})\end{array}$ & $\begin{array}{c}\text { Resonant Frequency } \\
(\mathrm{GHz})\end{array}$ & $\begin{array}{c}\text { Bandwidth Percentage } \\
(\%)\end{array}$ \\
\hline HFSS & $14.25-15.15$ & 14.59 & 5.74 \\
& $18.27-23.74$ & 21.08 & 25.82 \\
CST & $13.97-14.80$ & 14.38 & 5.67 \\
& $18.05-23.17$ & 20.16 & 25.69 \\
Measured & $14.25-15.25$ & 14.7 & 5.9 \\
& $18.25-22.50$ & 19.5 & 25.34 \\
\hline
\end{tabular}


The dual-band elliptical antenna has an ultra-wide band effect in the second band (high frequency) with a bandwidth percentage of $25 \%$ and a bandwidth of $5.47 \mathrm{GHz}$.

Table 3. Comparison of previous designs with the proposed antenna.

\begin{tabular}{|c|c|c|c|c|c|}
\hline Ref. & Substrat $\left(\boldsymbol{\varepsilon}_{\boldsymbol{r}}\right)$ & $\begin{array}{l}\text { Antenna Area } \\
\left(\mathbf{m m}^{2}\right)\end{array}$ & $\begin{array}{c}\text { Resonant Frequency } \\
(\mathrm{GHz})\end{array}$ & $\begin{array}{l}\text { Bandwidth } \\
\text { (GHz) }\end{array}$ & Gain $(\mathrm{dB})$ \\
\hline [14] & 10.0 & $17 \times 17$ & $\begin{array}{l}12.94 \\
19.04\end{array}$ & $\begin{array}{l}2.38 \\
1.56\end{array}$ & $\begin{array}{c}3.1 \\
4.13\end{array}$ \\
\hline$[15]$ & 10.2 & $8.5 \times 7.96$ & $\begin{array}{l}13.62 \\
16.33\end{array}$ & $\begin{array}{c}0.576 \\
0.54\end{array}$ & $\begin{array}{l}3.53 \\
5.56\end{array}$ \\
\hline [16] & 2.2 & $9 \times 7.96$ & $\begin{array}{l}12.54 \\
14.15\end{array}$ & $\begin{array}{l}0.09 \\
0.06\end{array}$ & $\begin{array}{c}5 \\
4.6\end{array}$ \\
\hline [17] & 4.6 & $20 \times 15$ & $\begin{array}{c}15.15 \\
18.2\end{array}$ & $\begin{array}{l}1.9 \\
1.5\end{array}$ & $\begin{array}{c}5.9 \\
3.37\end{array}$ \\
\hline$[18]$ & 10.2 & $40 \times 35$ & $\begin{array}{l}13.0 \\
18.1\end{array}$ & $\begin{array}{l}4.4 \\
1.97\end{array}$ & $\begin{array}{l}2.03 \\
3.65\end{array}$ \\
\hline This work & 4.4 & $10 \times 12$ & $\begin{array}{c}14.44 \\
21.005\end{array}$ & $\begin{array}{l}0.829 \\
5.126\end{array}$ & $\begin{array}{c}5.59 \\
5.048\end{array}$ \\
\hline
\end{tabular}

The performance comparison between the proposed antennas with other antennas validated in the literature are shown in Table 3 Reviewing the optimized parameters, the proposed antenna offer much wider bandwidths with adequate gain and significantly smaller compared to reported antennas.

\section{CONCLUSION}

A new small dual band elliptical patch antenna for $\mathrm{Ku} / \mathrm{K}$ band applications has been presented in this paper. The proposed antenna has a simple structure and a small size of $10 \times 12 \times 1.58 \mathrm{~mm}^{3}$, on FR4 substrate. The design and optimization of the proposed antenna characteristics were examined and verified using two different electromagnetic solvers, and compared by the measured of the prototype.

The results show that the frequency bandwidth covers the Ku band (14.07-14.89) GHz and the $\mathrm{K}$ band $(18.27-23.74)$ at $14.59 \mathrm{GHz}$ and $21.08 \mathrm{GHz}$, with a return loss of $-33.97 \mathrm{~dB}$ and $-42.60 \mathrm{~dB}$ respectively, a maximum value gain of $7.4 \mathrm{~dB}$ at $18.89 \mathrm{GHz}$ and an global efficiency level of around $80 \%-92 \%$ in the frequency bands.

The characteristics of the proposed antenna from the simulated and measured data show that the dualband elliptical antenna can be a promising basic for many services required for $\mathrm{Ku} / \mathrm{K}$ band satellite applications.

\section{ACKNOWLEDGMENTS}

We thank the members of the IETR (Rennes Institute of Electronics and Telecommunications), University of Rennes1, France, for their cooperation, and for allowing us to use all the instruments and software available in their laboratory.

\section{REFERENCES}

[1] N. Moynier and P. Lorent, “Telecommunications par Satellite Applications Militaires", 28/02/2011.

[2] NSR.LLC, Global Assessment of Satellite, Supply \& Demand 9th edition, USA: NSR,LLC, 2012.

[3] R. Ilham and A. Kurniawan, "Design and implementation of microstrip antenna array on Ku-Band for satellite TV reception", in Telecommunication Networks and Applications Conference (ITNAC), 2015 International, pp. 185-190, 2015.

[4] U. Rafique and H. Khalil, "Dual-band Microstrip Patch Antenna Array for 5G Mobile Communications", Progress in Electromagnetics Research Symposium, pp. 5, 2017.

[5] A.I Yussuff, I.E Koleoso, N.H.H Khamis, “ Investigating Rain Attenuation Models for Satellite Links in Tropical Nigeria," Indonesian Journal of Electrical Engineering and Informatics (IJEEI), Vol.6, No.1, March 2018, pp.61 69

[6] C.A. Balanis, Antenna Theory: Analysis and Design, 3rd ed Wiley, New York, USA, 2005.

[7] Z. Er-Reguig, H.Ammor, "A Multi-element Microstrip Antenna for LTE Bands, Wi-Fi and WiMAX Application in Femtocell Network," Indonesian Journal of Electrical Engineering and Informatics (IJEEI), Vol.6, No.2, June 2018, pp. $183 \sim 189$

[8] S. Alam, I. Surjati, A. Ferawan, T. Firmansyah, "Design and Realization of Compact Microstrip Antenna Using Fractal Sierpenski Carpet For Wireless Fidelity Application," Indonesian Journal of Electrical Engineering and Informatics (IJEEI), Vol.6, No.1, March 2018, pp.70 78

[9] M.Meloui and M Essaaidi. "A dual ultra wide band slotted antenna for C and X bands application", Progress in In Electromagnetics Research Letters, Vol. 47, pp 91-96, 2014.

[10] R. Deng, S. Xu, and F. Yang, "Design of a Ku/Ka quad-band reflectarray antenna for satellite communications," IEEE International Symposium on Antennas and Propagation, pp. 1217-1218, October 2016. 
[11] R.P. Dwivedi, U.K. Kommuri and Veeramani, "Design and Simulation of Wideband Patch Antenna far Wireless Application," IEEE, 2nd International Conference on Signal Processing and Integrated Networks (SPIN), pp. 1518, February 2015.

[12] R.P. Dwivedi, U.K. Kommuri and Veeramani, "Design and Simulation of Wideband Patch Antenna far Wireless Application," IEEE, 2nd International Conference on Signal Processing and Integrated Networks (SPIN), pp. 1518, February 2015.

[13] B. Winter and V. Stoiljkovic, "A novel dual band antenna for mobile communications," IEEE Antennas and Propagation Society International Symposium, Vol. 2, pp. 778-781. 1998.

[14] M. R. Ahsan, M.T. Islam, M.H. Ullah, " A simple design of planar microstrip antenna on composite substrate for $\mathrm{Ku} / \mathrm{K}$ band satellite applications," International Journal of Communications Systems, 2015. DOI: 10.1002/dac.2970

[15] Samsuzzaman M, Islam MT, Yatim B, Ali MM. "Dual frequency triangular slotted microstrip patch antenna for Ku band applications", Przeglad Elektrotechniczny, Vol. 89, Issue number 1, pp.275-279. 2013.

[16] Islam MT, Misran N, Mobashsher AT, “Compact dual band microstrip antenna for Ku-band application”, Information Technology Journal Vol.9 N², pp.354-358. 2010.

[17] M. Habib Ullah, M.T. Islam, M.R. Ahsan, J.S. Mandeep, and N. Misran, N. "A dual band slotted patch antenna on dielectric material substrate", International Journal of Antennas and Propagation, Volume 2014, pp. 1-7, January 2014.

[18] M. R. Ahsan, M. T. Islam, M. Habib Ullah, R. W. Aldhaheri and M. M. Sheikh, "A new design approach for dualband patch antenna serving $\mathrm{Ku} / \mathrm{K}$ band satellite communications," International Journal of Satellite Communications and Networking., vol. 34, no. 6, pp. 759-769, August 2015.

[19] https://www.anritsu.com/en-US/components-accessories/products/3680-series 